\title{
Centrifuge liquefaction tests in a laminar box
}

\author{
B. HUSHMAND, ${ }^{*}$ R. F. SCOTT $\dagger$ and C. B. CROUSE*
}

\begin{abstract}
The difficulties associated with instrumenting earthquake sites in order to record pore pressure changes in a future event led to the use of scaled model tests performed in a centrifuge. Both dry and saturated sands were employed, contained in a box constructed of aluminium laminae designed to move freely on each other. This would result in shearing distortions developing in the soil unimpeded by the container. Accelerometers, displacement transducers and pore pressure sensors were attached to the box and embedded in the soil at various elevations so as to record the response of the soil to an earthquake-like excitation supplied to the base of the container. A special apparatus was constructed to imitate earthquake motion. In some tests on saturated sand, the soil profile was liquefied. Test results of accelerations, lateral and vertical displacements and pore pressures against time for typical earthquake inputs are given. The data, obtained under controlled conditions, can be compared with the various calculation methods for dynamically generated pore pressures.
\end{abstract}

KEYWORDS: centrifuge modelling; earthquakes; granular materials, liquefaction; pore pressures; site response.
Des essais en modèle réduit furent effectués pour étudier les difficultés associées à l'instrumentation des emplacements séismiques afin d'enrigistrer les changements dans la pression interstitielle lors d'un éventuel tremblement de terre. Des sables secs aussi bien que des sables saturés furent employés qui étaient renfermés dans une boîte formée de lamelles d'aluminium pouvant se déplacer librement les unes sur les autres en sorte de produire des distorsions par cisaillement dans le sol qui n'étaient pas limitees par la boîte même. Des accélétomètres, des transducteurs de déplacement et des senseurs de pression interstitielle furent attachés à la boîte et posés dans le sol à des hauteurs différentes pour l'enrigistrement de la réponse du sol à un ébranlement type tremblement de terre causé à la base de la boîte. Un appareil spécial fut construit pour imiter le mouvement d'un tremblement de terre. Dans certains essais effectués sur du sable saturé le profil du sol fut liquéfié. L'article présente les résultats des essais concernant les accélérations, les déplacements latéraux et verticaux et les pressions interstitielles tracés en rapport au temps pour des événements séismiques typiques. Les données, obtenues sous des conditions contrôlées, peuvent se comparer à de différentes méthodes de calcul pour des pressions interstitielles d'origine dynamique.
Earthquake-generated liquefaction of soils has been widely observed and the mechanisms have been studied intensively since the 1964 Niigata earthquake, which first attracted the attention of engineers to the phenomenon. In the last 20 years, cyclic triaxial and cyclic simple shear tests have been widely used to study the liquefaction characteristics of soils. Simplified procedures (Seed \& Idriss, 1971) as well as a variety of more complicated numerical methods (DESRA: Lee and Finn, 1975, 1978; Finn, Lee \& Martin, 1977; GADFLEA: Booker, Rahman \& Seed, 1976; TARA: Siddharthan and Finn, 1982; Finn, Siddharthan, Lee \& Schofield, 1984) have been proposed to

Discussion on this Paper closes on 1 October 1988. For further details see $\mathrm{p}$. ii.

* Earth Technology Corporation, Long Beach.

† California Institute of Technology, Pasadena. investigate the liquefaction potential at specific sites under postulated earthquake or ground motion conditions. Such methods are based on semi-empirical methods of describing the soil behaviour, in which values for the required properties are obtained from the results of cyclic laboratory tests on soil samples. Adjustment of laboratory parameters to reflect sample disturbance, or the use of reconstituted samples, is sometimes made using results from in-place field tests such as the soil penetrometer test (SPT) or cone penetrometer test (CPT).

Calibration of the analytical techniques is achieved by their utilization in predicting the occurrence or absence of liquefaction at specific sites where liquefaction has or has not already been observed during past earthquakes. Such comparisons are frequently unsatisfactory because the detailed soil profile and properties at 
selected sites are inadequately known, or because the ground motion at the sites has not been recorded and therefore must be obtained from generalized data for intensity of shaking against distance for the relevant earthquake magnitude (Seed \& Idriss, 1982). There is therefore some uncertainty as to the accuracy of any particular numerical program in predicting either pore pressure increases with time, or the onset of liquefaction.

A proper calibration test would require application of the calculation technique to an instrumented site where in-place soil properties had been appropriately established, and where ground motions had been measured for an earthquake strong enough to have generated significant increases in the normal pore pressures. Unfortunately, suitable test devices for measuring cyclic soil properties in the ground have yet to be developed. The instrumentation would preferably include pore pressure gauges with a response rapid enough to keep up with the earthquake motions, and strong motion accelerometers; both being installed at various depths. It would also be desirable to record total soil stresses during shaking, but the unreliability of stress gauges embedded in soil, particularly when recording fluctuating stresses, would seem to preclude this (Weiler \& Kulhawy, 1982).

The difficulty with the preferred technique of calibrating an analysis is the uncertainty of earthquake occurrence. Even at a site which might, on the basis of previous experience, have a high probability of undergoing seismic motions strong enough to perturb the ambient pore pressures, the instrumentation will probably have to wait for years before the anticipated event occurs. Therefore, the question of equipment reliability and automatic operation becomes very important, and the costs of instrumentation are clearly very high. In addition, the awaited ground motion may in reality be too small, or even unacceptably large. To date, the literature contains only a single case of an instrumented site; Owi Island, Japan (Ishihara, Shimizu \& Yamada, 1981) experienced an earthquake which was recorded, although it seems that other records have been obtained recently in Taiwan. Even at Owi Island, where the equipment had been installed for only two years, two of the pore pressure gauges malfunctioned. The data are, however, valuable for test calibration purposes.

In the past, attention has been given to the use of laboratory experiments involving shaking tables (Finn, Emery \& Gupta, 1971; Sasaki \& Taniguchi, 1981) as an improved means of liquefaction evaluation. Although pore pressures and liquefaction have been generated in such tests, questions arise about the relevance of these studies to the behaviour of the prototype, as stresses in laboratory tests are developed in layers approximately $1 \mathrm{~m}$ deep. More recently, attention has been given to the centrifuge testing technique as it offers the possibility of carrying out experiments at stresses in the range of those encountered in soil profiles in the field. Liquefaction test series have been performed on the Cambridge University centrifuge (Lambe, 1981) using a soil test box of circular cross-section built of rings coated with Teflon. The intention was to construct an apparatus which would respond substantially as a one-dimensional shearing container. Tests indicated that the containers as built, with a width-to-depth ratio of unity, responded mostly in shear to an input base motion. Accelerations, pore pressures and soil settlement were recorded when the box was shaken for approximately 10 cycles of sinusoidal motion on the Cambridge University 'bumpy road' apparatus (Schofield, 1980, 1981). Similar experiments in a similar box apparatus were conducted by Arulanandan, Anandaraj \& Abghari (1983) using a base excitation supplied by a Davis piezo-electric shaker.

In 1981-82, an electrohydraulic shaking apparatus was developed for the California Institute of Technology $1 \mathrm{~m}$ radius centrifuge (Aboim, Scott, Lee \& Roth, 1986). The equipment has the capability of subjecting test specimens or models to vibrations which, with proper scaling, simulate the duration, intensity and spectral shape of real earthquake accelerograms. The opportunity arose to conduct liquefaction tests on the centrifuge with this shaking equipment. However, it was considered appropriate to construct a test container that was different from that used in previous centrifuge investigations.

\section{TEST CONTAINER}

After review of the circular ring design used by previous investigators (Lambe, 1981; Whitman, Lambe \& Kutter, 1981; Arulanandan et al., 1983) it was thought desirable both to increase the length-to-depth ratio of the liquefaction container to reduce possible cantilever deformations, and to make the shape rectangular in order to enhance the one-dimensional response. A sketch of the design, with dimensions, is shown in Fig. 1(a). Since the circular Teflon-coated rings employed previously had to be subjected to a vertical clamping force to ensure a good seal between the rings, there was a question as to the actual frictional force developed between the rings at the increased $g$ acceleration of the experiments. This force, which was not measured in previous experiments, interferes with the soil response. The rectangular arrangement of the new apparatus 

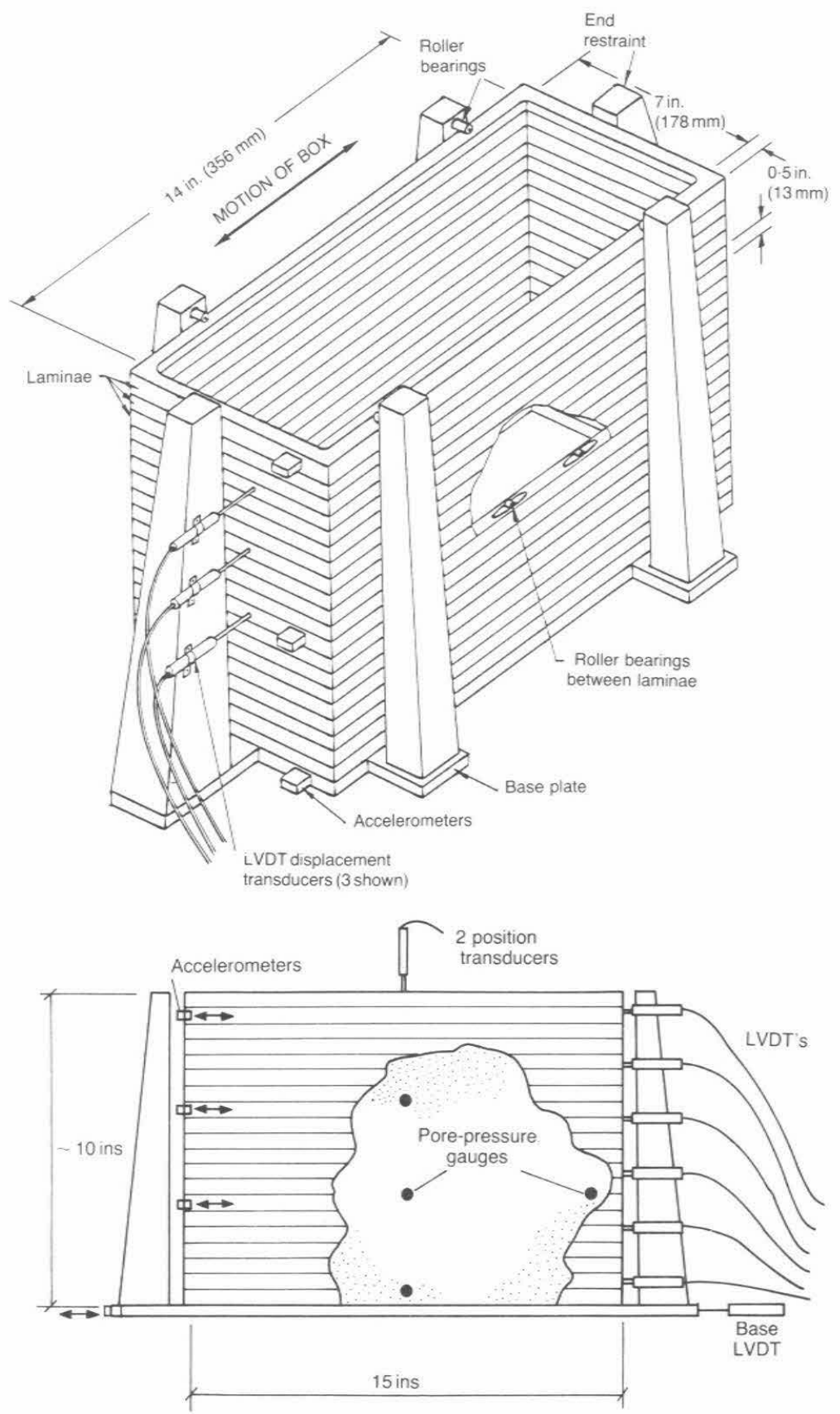

Fig. 1: (a) Sectional view of the laminar box showing some transducer locations; (b) Location of other transducers during tests

permitted the possibility of reducing the friction between adjacent layers of the box by placing bearings between them. The intention was that the container should play little part in the response of the soil system. Consequently, a number of grooves were machined in each alu- minium plate to a depth equal to slightly less than the bearing radius. As the plates were chosen to be 0.5 inches $(12.7 \mathrm{~mm})$ thick, a bearing diameter smaller than this dimension was required and 0.250 inch $(6.35 \mathrm{~mm})$ diameter bearings were employed. A slightly larger size would 
further decrease the resistance to horizontal movement between plates.

A wide range of materials could have been used, but in practice readily obtainable steel bearings were chosen. It would have been desirable either to have anodized the aluminium laminae to increase their surface hardness, or to have placed steel inserts at the bottom of the grooves as supports for the bearings. However, in the interests of economy it was decided to omit this step until a trial had been conducted on the efficacy of the selected system. Spherical bearings were initially employed, but preliminary tests showed that they indented the lowest plates sufficiently to let the plates come into contact. The spherical bearings were therefore replaced with cylindrical bearings 0.25 inches $(6.35 \mathrm{~mm})$ in diameter and length. A series of tests was performed to measure the force required to translate each plate relative to its neighbours when the box was empty. Each plate at a particular height from the bottom of the box was pushed by a pneumatic piston while keeping the other plates fixed in the centre position. The applied force was measured by a load cell positioned between the piston and the plate. The tests performed after replacing the ball bearings with cylindrical bearings showed a marked reduction in the force required to overcome friction between plates. The final friction coefficient between plates near the base of the laminar box, at $50 \mathrm{~g}$, was found to be 0.013 .

The possibility of conducting tests on a soil dense enough to dilate in shear was considered. This might cause individual confining laminae to separate and consequently a vertical restraint on the plate stacks was included in the design. Small roller bearings with horizontal axes, attached to four vertical supports at the side of the container, bear on the top plate. They are adjustable in the vertical direction, and are usually set to provide a small contact force on the top plate at $1 \mathrm{~g}$ conditions. At elevated $g$ levels in flight, there is probably a clearance of several thousandths of an inch $(0 \cdot 1-0.2 \mathrm{~mm})$ between the bearing surface and the plate (see Fig. 1(a)).

As a completely liquefied soil has only a small lateral shearing resistance, it might be expected that substantial horizontal displacements would occur in the soil column (or laminated box). It was decided to limit the possible excursions by providing an extended vertical stop at each end of the box in the long direction. A movement of 1 inch $(25.4 \mathrm{~mm})$ in each direction was selected arbitrarily. With a 10 inch $(254 \mathrm{~mm})$ vertical height consisting of 20 plates, each 0.5 inch $(12.7 \mathrm{~mm})$ thick, a maximum thickness of prototype soil layer of about $41 \mathrm{ft}(12.7 \mathrm{~m})$ at $50 \mathrm{~g}$, and $62 \mathrm{ft}(18.9 \mathrm{~m})$ at $75 \mathrm{~g}$ was simulated. The maximum allowable prototype horizontal dis- placement from the initially centred position was 50 inches $(1270 \mathrm{~mm})$ and 75 inches $(1905 \mathrm{~mm})$ respectively at these two acceleration levels. These displacements were not exceeded in preliminary tests with saturated sand fully liquefied under a realistic model earthquake excitation. Further tests may require the horizontal displacement tolerance to be relaxed. The maximum lateral travel of one aluminium lamina with respect to its neighbours permits a total horizontal displacement at the top of the 20 plate stack of 3.5 inches $(88.9 \mathrm{~mm})$, if all the plates were to undergo an extreme excursion in one direction, without restraint, from a position in which all bearings were centred.

When the box was being assembled, the bearings were brought to their centre position by the simple procedure of moving the uppermost plate (as the stack is being built) on its bearings to the left and right limits of its travel, and then back to the centre, while the underlying plates were held in the centred position. When the stack was complete, it was locked against lateral displacement by inserting 1 inch $(25.4 \mathrm{~mm})$ wide spacer bars between the box and the vertical end restraining posts. These bars could also be left in place in flight so as to convert the laminar box to a normal soil container, if desired. A base plate, to which the side and end posts were attached and on which the box was mounted, was bolted to the moveable platform of the centrifuge shaking mechanism.

Specially made disposable plastic bags, a few millimetres larger than the inside dimensions of the container, contained the soil in the box. These were about $150 \mathrm{~mm}$ deeper than the box and the surplus material at the top was drawn down over the container walls to protect the bearings from the fine sand of the test specimens. In the tests, sand was placed in the plastic bag by raining or spooning; for the saturated sand tests, the sand and water mixture was ladled into the container from a deaired saturated sand reservoir. Computation shows that, under a uniformly distributed pressure of $1 \mathrm{lb} /$ in length $(175 \mathrm{~N} / \mathrm{m})$ a single lamina will deflect 0.00446 in $(0.11 \mathrm{~mm})$ outward at the center of the long side, and 0.00097 in $(0.02 \mathrm{~mm})$ inward at the centre of the short side, in the absence of any assumed three-dimensional restraint offered by the bearings. Thus, at $50 \mathrm{~g}$, complete liquefaction of the saturated sand will cause a calculated maximum deflection of the center of the long side at the base of about 0.068 in $(1.7 \mathrm{~mm})$ giving a deflection to length ratio of $0.5 \%$. This is a conservative value, ignoring the restraint contributed by the bearings, and appears small enough to minimize concern about the one-dimensional nature of the motion generated. 


\section{PRELIMINARY TESTS}

Preliminary tests were run on dry and saturated fine Nevada sand to examine the performance of the equipment. The fine sand is uniform, has a mean grain size of $0.1 \mathrm{~mm}$ and minimum and maximum void ratios of 0.53 and 0.88 respectively. In the tests, four single-axis miniature accelerometers were placed at the base, one-third depth, two-thirds depth, and at the top of the soil column. To measure dynamic lateral displacements, six linear variable differential transformers (LVDT) were attached at equal vertical intervals to one of the end stops (see Fig. 1). Their cores were attached to threaded nylon rods screwed into the individual plates comprising the box. A seventh LVDT measured the relative displacement of the seismic platform with respect to the frame of the shaking device. Each LVDT provided a history of horizontal displacement at the soil level at which it was located, relative to the seismic platform. The displacements of all the LVDT's at a single time provided a snapshot of the displaced shape of the soil column. In addition, two linear position transducers (potentiometers) were used to measure the settlement of the soil surface.

During the saturated sand tests, these transducers were supplemented by four pore pressure transducers, 0.25 inches $(6.35 \mathrm{~mm})$ in diameter and 0.5 inches $(12 \mathrm{~mm})$ long, located at the column base, and at one-third and two-thirds of the soil depth. These gauges, which are cylindrical in shape, were arranged with the circular pressure-sensing face vertical and the leads, exiting from the circular base, positioned horizontally at right angles to the shaking direction. While it is impossible to locate any measuring device in soil without causing a state of stress adjacent to the gauge, it was believed, in the case of small pore pressure transducers in particular, that the effect was minimal with regard to the observed pressures. The gauges employed had a density of $100 \mathrm{lb} / \mathrm{ft}^{3}$, which is close to that of saturated soil. In an actual test, the density difference results in movement of the transducer with respect to the soil when liquefaction occurs. Transducer locations are shown in Fig. 1(b). Signals from all the transducers were amplified and filtered to eliminate high frequency noise, passed through slip rings and then recorded digitally by a high speed analogue-to-digital converter $(\mathrm{ADC})$ and a microcomputer system.

Some of the measurements made in two tests on a dry and a saturated Nevada fine sand are shown. The dry sand had an initial $1 g$ dry unit weight of $92.5 \mathrm{lb} / \mathrm{ft}^{3}\left(14.53 \mathrm{kN} / \mathrm{m}^{3}\right)$ with a relative density of $26 \%$, and was placed to a depth of 8.7 inches $(221 \mathrm{~mm})$. It was shaken at $75 \mathrm{~g}$ centrifugal acceleration by a model earthquake with equiva- lent prototype base acceleration history as shown in Fig. 2. The soil accelerations at the two intermediate levels and the top surface are also illustrated. This excitation caused a prototype surface settlement of 17 inches $(0.43 \mathrm{~m})$ (Fig. 3). Horizontal displacements, recorded by the LVDT's at the base, midheight and top of the soil, are given in Fig. 4; the soil displacements must be added to the base motion for an absolute measure of displacement. Fig. 5 shows several snapshots of the soil profile at the prototype times given. The input acceleration corresponds in frequency content and duration to, but is slightly more intense than, the N-S component of the $1940 \mathrm{El}$ Centro accelerogram.

A similar test, at $50 \mathrm{~g}$, was conducted on saturated sand in which pore pressure transducers were added to the previous instrumentation. The $1 g$ total unit weight of the soil in this test, after consolidation at $50 \mathrm{~g}$, was $123 \mathrm{lb} / \mathrm{ft}^{3}(19.33 \mathrm{kN} /$ $\mathrm{m}^{3}$ ), corresponding to a relative density of $54 \%$. Figs 6-10 show the accelerations, displacements at various heights, displacement profiles at different times, pore pressure histories, and settlement at the centre of the profile. The maximum pore pressures shown at the base correspond to the total pressure of soil and water, indicating that the entire soil column liquefied. Horizontal displacements are seen to be correspondingly larger than those observed for dry sand. Following the excitation, the pore pressures decay as the sand grains settle into contact with one another to form a continuous granular structure once more (solidification) (Scott, 1986a and 1986b). In this test the final surface settlement was 27 inches $(0 \cdot 69 \mathrm{~m})$ (see Fig. 10).

However, the change in the surface geometry of the soil accounts for part of this settlement, as distinct from the behaviour of the dry sand. The saturated sand sample was prepared with a horizontal surface, but when liquefaction was complete, the liquefied soil formed a cylindrical surface during flight with a radius of approximately 36 inches $(0.91 \mathrm{~m})$ from the vertical centrifuge axis. After liquefaction, the $50 \mathrm{~g}$ centrifugal acceleration was maintained long enough for the soil to solidify. Accordingly, when the centrifuge was stopped, the cylindrical surface was preserved. If it is assumed that the soil underwent no volume change in the few (prototype) seconds during which it liquefied, then the settlement at the centre due to the change from a flat to a cylindrical surface may be calculated to be approximately 0.228 inches $(5.8 \mathrm{~mm})$ model or 11.4 inches $(0.29 \mathrm{~m})$ prototype scale. This probably occurred quite rapidly in the centrifuge, and perhaps accounts for the settlement recorded in Fig. 10 centred on the 8 second mark on the scale. The settlement due to sedimentation is 


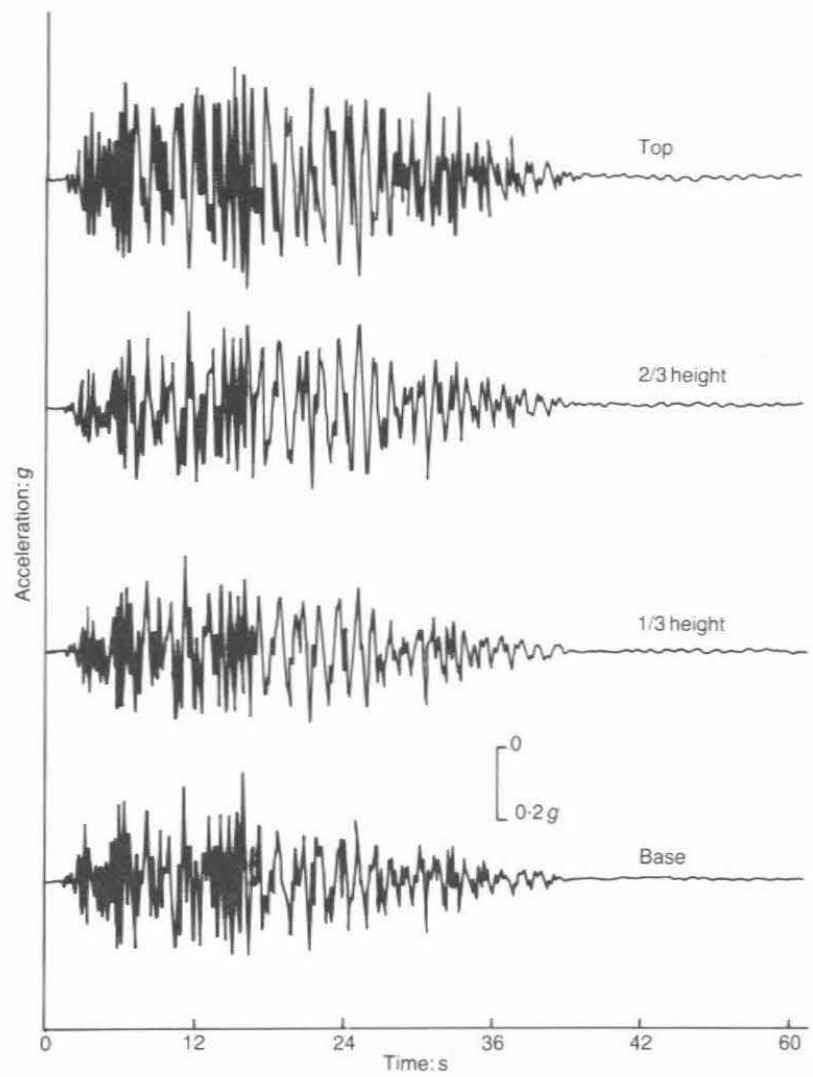

Fig. 2. Prototype accelerograms generated during earthquake simulated shaking of a dry sand column

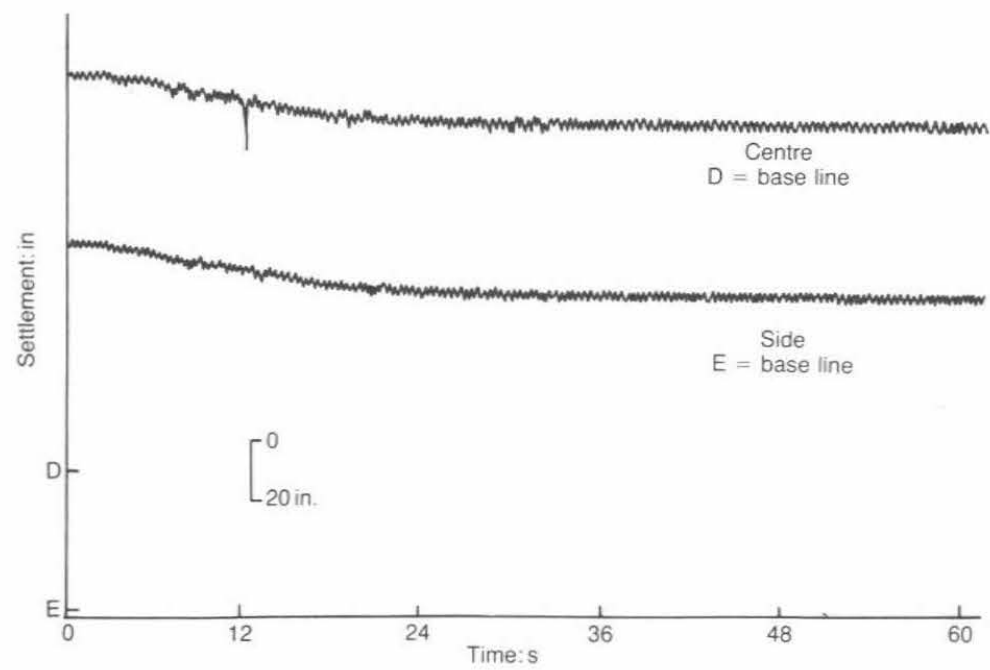

Fig. 3. Prototype settlement of a dry sand column measured at side and centre of the soil surface during shaking 


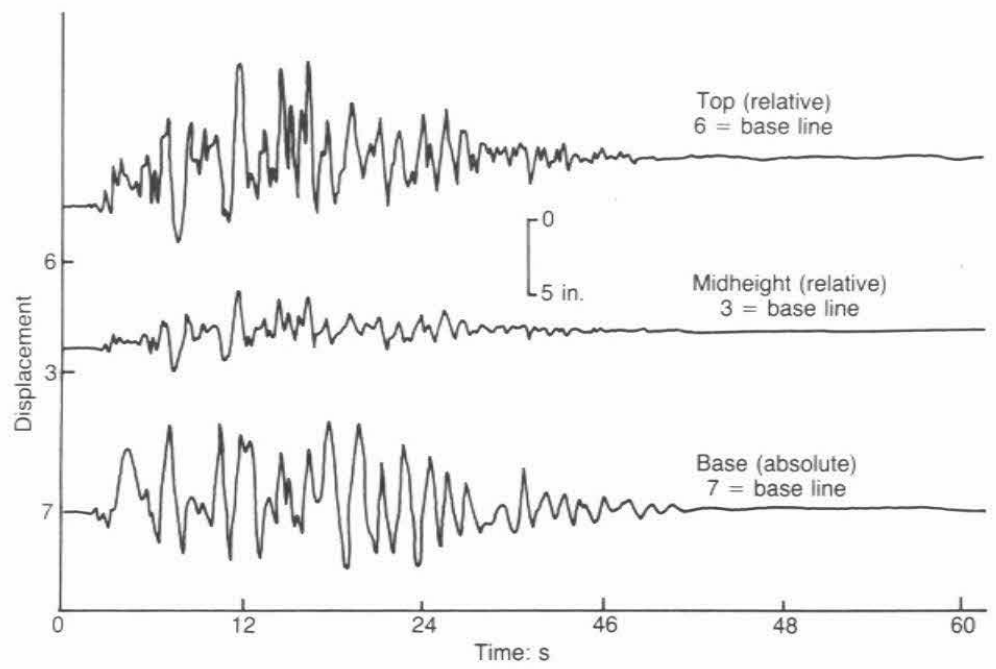

Fig. 4. Prototype horizontal displacement histories of a dry sand column during earthquake simulated shaking

obtained from the difference between the total settlement observed and that due to the curvature of the soil surface, as follows. The total liquefaction settlement is indicated to be $27-11.4=15.6$ inches $(0.40 \mathrm{~m})$ or about $3.5 \%$ of the height of the soil column, which corresponds to an increase in the relative density of the soil to $70 \%$.

The geometrical changes in the soil surface for the test configuration employed indicate that no surface elevation change (due to formation of a cylindrical surface) occurs at points approximately 4 inches $(102 \mathrm{~mm})$ model scale to each side of the test box centreline. In subsequent tests, vertical surface movement will be measured at similar points, giving better indications as to the correct soil settlement.

It can be seen in Fig. 9 that the detailed structure of the responses indicated by the pore pres-
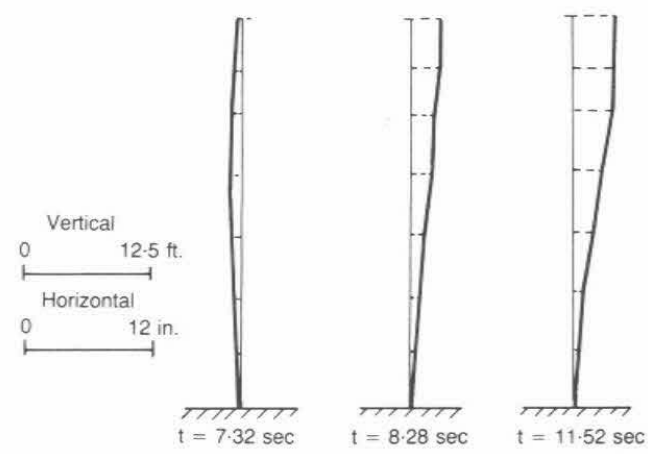

Fig. 5. Prototype displacement profiles of a dry sand column at various prototype times during shaking sure transducers at the bottom and at one-third (side) height is different from that of the two gauges at the one-third (centre) and two-thirds (centre) height. The transducers employed were all of the same type, with similar calibration constants and the same amplification of electrical output signals. They also exhibited the same episodes of electrical glitches; for example, just before the 24 second mark. It is concluded that the difference between the two data sets is real and is due to the position of the gauges. The transducers at the bottom and at one-third (side) height are either mechanically in contact with the metal base or side of the box, or are very close to them, whereas the other two gauges are in the middle of the soil mass. It seems probable that the high frequency fluctuations observed while the soil is liquid are due to compression (P) waves generated in the liquid by the vertical vibration of the soil container. At the metal surfaces the intensity of vibration is greater than in the centre of the soil where a lower amplitude is observed as a result of dissipation occurring as the waves pass through the soil mass.

\section{CONCLUSIONS}

A new laminar soil testing box has been constructed for centrifuge tests. Cantilever deformations are minimized with a box length-to-depth ratio of about 2 . The placing of bearings between the layers of the box reduced the interlayer friction coefficient of the plates from about 0.04 (Teflon coated without bearings) to a measured value of 0.013 under the loads experienced in the centrifuge tests. 


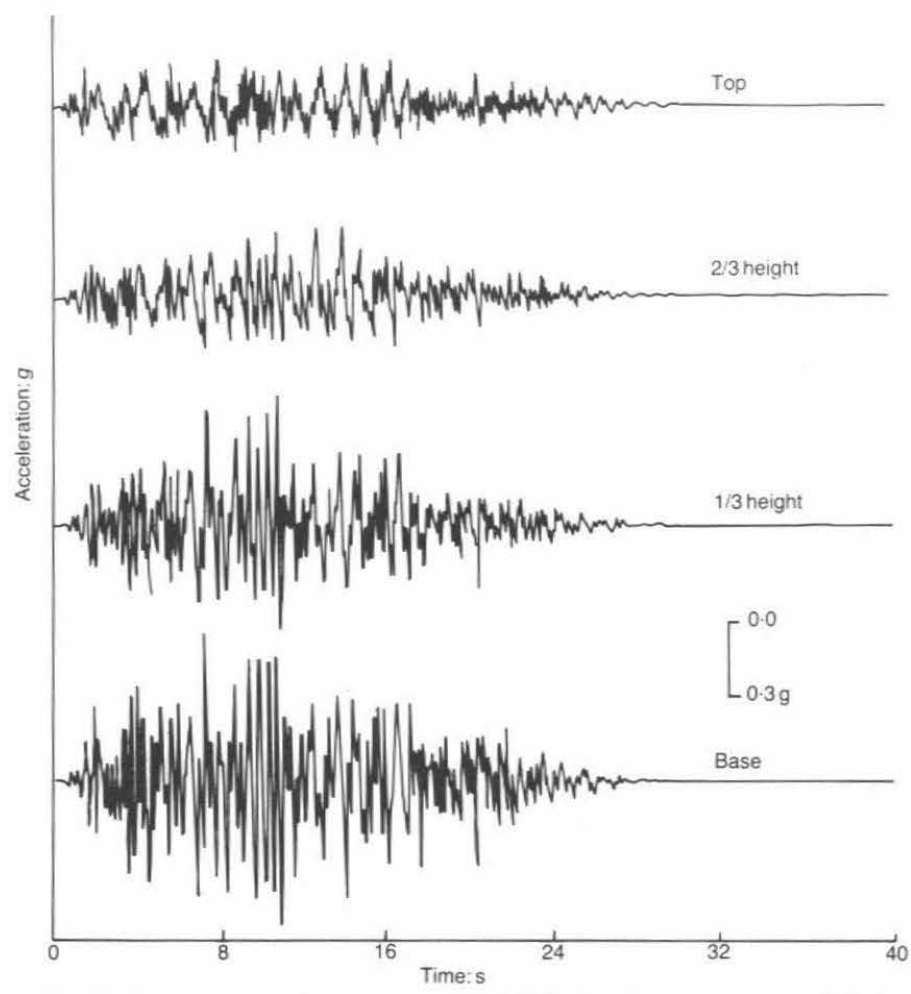

Fig. 6. Prototype accelerograms generated during the saturated sand test

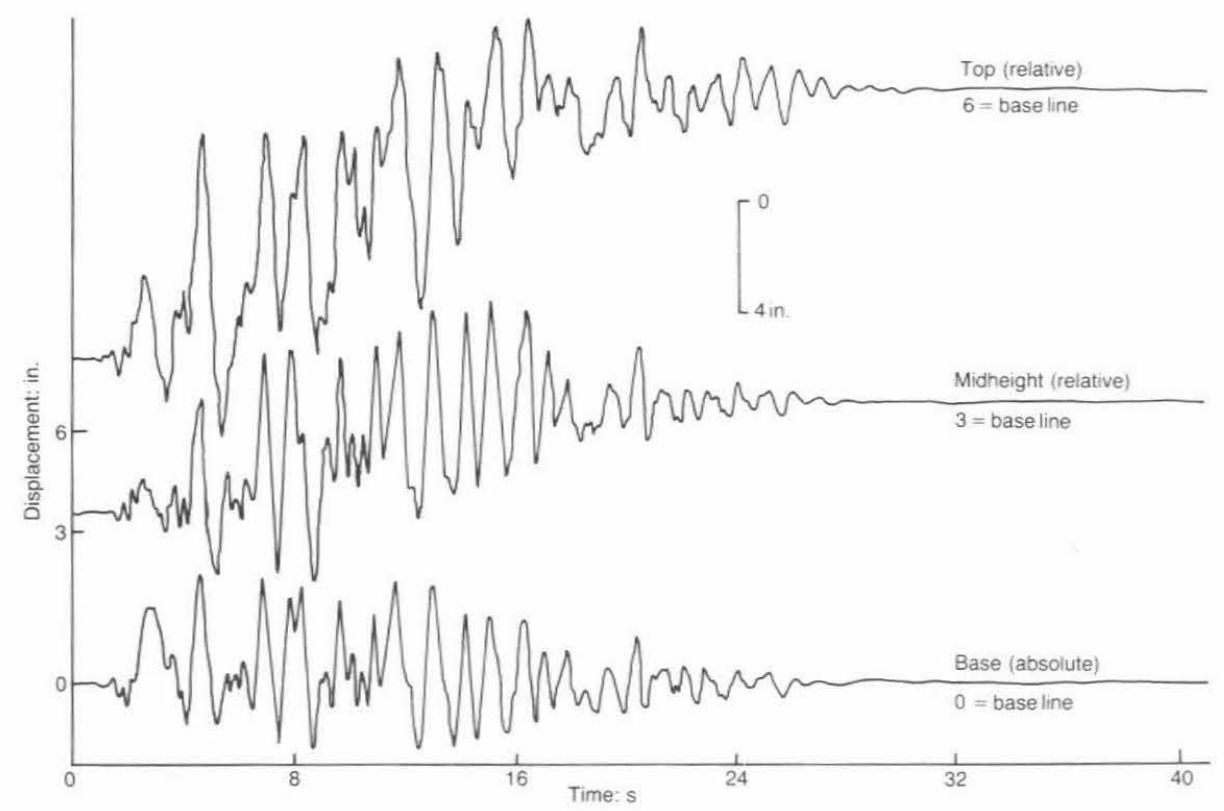

Fig. 7. Prototype horizontal displacement histories of a saturated sand column 

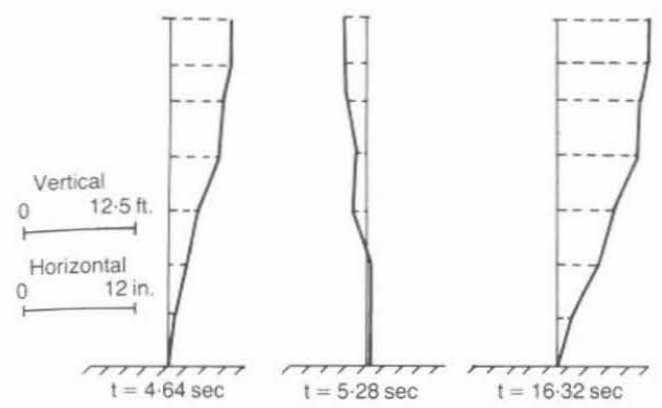

Fig. 8. Prototype displacement profiles of a saturated sand column at various prototype times during shaking
Other than reduced frictional resistance between layers, desirable features of the laminar box demonstrated by these tests are

(a) the virtually identical pore pressure responses of the gauges located at the one-third height near the LVDT's and at the centre of the box (see Figs 1(b) and 9)

(b) the similar behaviour of the two settlement transducers positioned in the centre and at the side of the top surface of the soil in the dry sand test (see Figs $1(\mathrm{~b})$ and 3 )

Other tests (not shown here) with accelerometers placed in the soil and at the side of the box at the

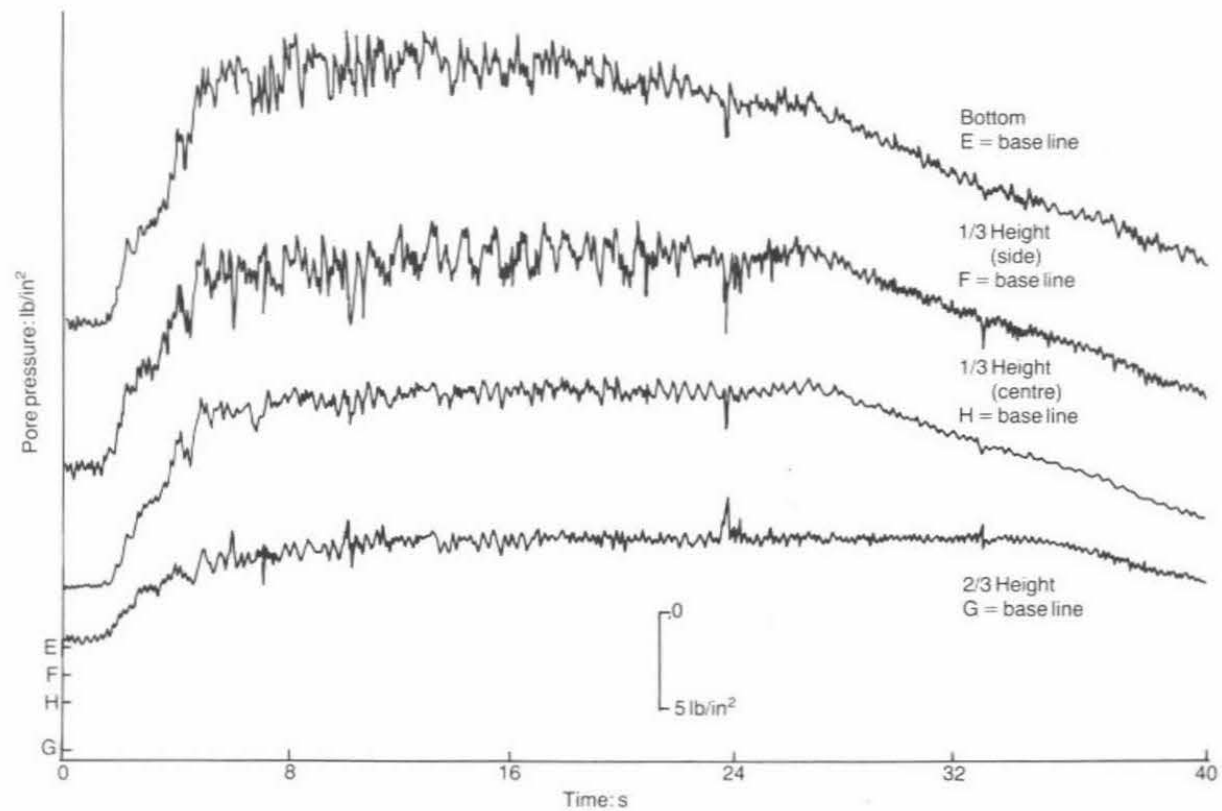

Fig. 9. Prototype pore pressure histories in a saturated sand column

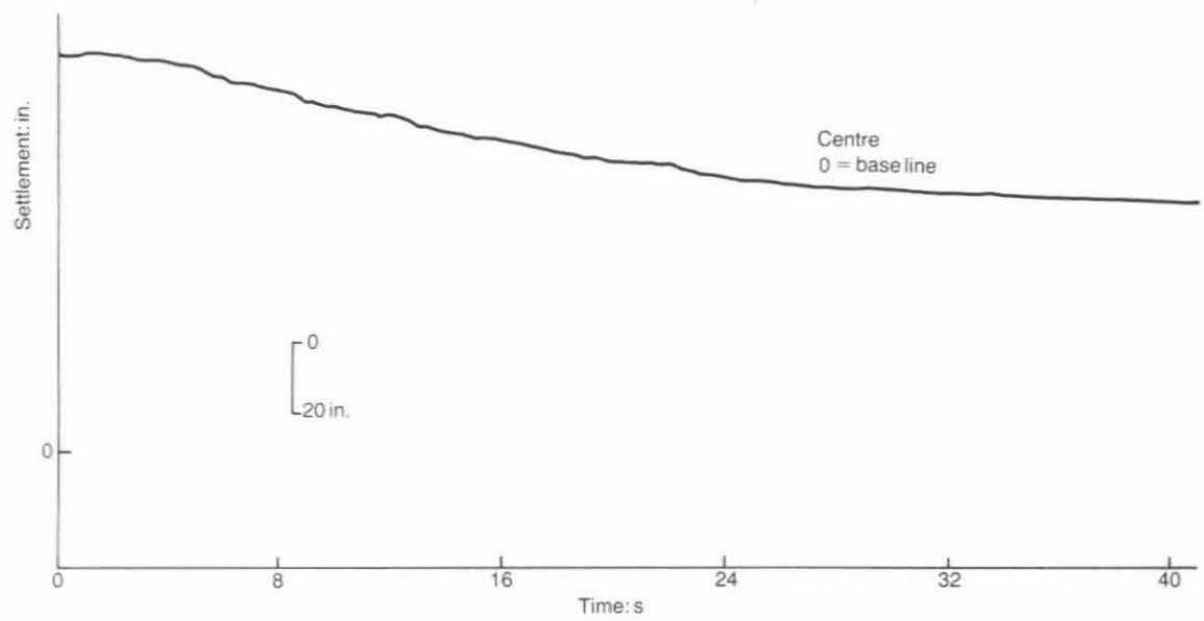

Fig. 10. Prototype settlement of a saturated sand column measured at the centre of the soil surface during shaking 
same elevation demonstrated the same degree of similarity. It is concluded from these data that the desired one-dimensional response of the laminar box is being attained.

The ability with such apparatus to make detailed measurements of all the responses of the soil system during base motion precisely controllable in amplitude, frequency content, and duration under prototype levels of stress will enhance the usefulness of the few real prototype tests available. More detailed analyses of the data provided by these and other tests may give rise to better understanding of the liquefaction process in soils.

\section{ACKNOWLEDGEMENTS}

This study was supported by the US Geological Survey under Grant No. 14-08-0001G1192. The laminar box was built by J. R. Lee, who also assisted in its design.

\section{REFERENCES}

Aboim, C., Scott, R. F., Lee, J. R. \& Roth, W. H. (1986). Centrifuge earth dam studies: earthquake tests and analysis. Final report, Grant No. CEE-7926691. Washington, DC: National Science Foundation.

Arulanandan, K., Anandaraj, A. \& Abghari, A. (1983). Centrifuge modelling of soil liquefaction susceptibility. J. Geotech. Engng Div. Am. Soc. Civ. Engrs 109, GT3, 281-300.

Booker, J. R., Rahman, M. S. \& Seed, H. B. (1976). GADFLEA - a computer program for the analysis of pore pressure generation and dissipation during cyclic or earthquake loading. Report No. EERC 76-24, Earthquake Engineering Research Center, University of California at Berkeley.

Finn, W. D. L., Emery, J. J. \& Gupta, Y. P. (1971). Liquefaction of large samples of saturated sand on a shaking table. Proc. Ist Can. Conf. Earthquake Engng, Vancouver 97-110.

Finn, W. D. L., Siddharthan, R., Lee, F. \& Schofield, A. N. (1984). Seismic response of offshore drilling islands in a centrifuge including soil-structure interaction. Proc. 16th Offshore Technol. Conf., Dallas 1, 399-406.

Finn, W. D. L., Lee, K. W. \& Martin, G. R. (1977). An effective stress model for liquefaction. J. Geotech. Engng Div. Am. Soc. Civ. Engrs 103, GT6, 517-533.
Ishihara, K., Shimizu, K. \& Yamada, Y. (1981). Pore water pressures measured in sand deposits during earthquake. Soils Fdns 21, No. 4, 85-100.

Lambe, P. C. (1981). Dynamic centrifuge modelling of a horizontal sand stratum. $\mathrm{ScD}$ thesis, Massachusetts Institute of Technology.

Lee, M. K. W. \& Finn, W. D. L. (1975). DESRA-1program for the dynamic effective stress response analysis of soil deposits including liquefaction evaluation. Soil Mechanics, No. 36.

Lee, M. K. W. \& Finn, W. D. L. (1978). DeSRA-2dynamic effective stress response analysis of soil deposits with energy transmitting boundary including assessment of liquefaction potential. Soil Mechanics, No. 38 .

Sasaki, Y. \& Taniguchi, E. (1982). Large scale shaking table tests on the effectiveness of gravel drains for liquefiable sand deposits. Proc. Conf. Soil Dyn. Earthquake Engng, Southampton 2, 843-857.

Schofield, A. N. (1980). Cambridge geotechnical centrifuge operations. Géotechnique 30, No. 3, 227-268.

Schofield, A. N. (1981). Dynamic and earthquake geotechnical centrifuge modelling. Proc. Int. Conf. on Recent Advances in Geotech. Earthquake Engng and Soil Dynamics 3, 1081-1100. Rolla: University of Missouri.

Scott, R. F. (1986a). Soil properties from centrifuge liquefaction tests. Mechanics of Materials 5, 199205.

Scott, R. F. (1986b). Solidification and consolidation of a liquefied sand column. Soils Fdns 26, No. 4, 23-31.

Seed, H. B. \& Idriss, I. M. (1971). Simplified procedure for evaluating soil liquefaction potential. J. Soil Mech. Fdns Div. Am. Soc. Civ. Engrs 97, SM9, 12491273.

Seed, H. B. \& Idriss, I. M. (1982). Ground motions and soil liquefaction during earthquakes. Monograph, Earthquake Engineering Research Institute, University of California at Berkeley.

Siddhartha \%, R. \& Finn, W. D. L. (1982). TARA-2-twodimensic nal nonlinear static and dynamic response analysis. Soil Dynamics Group. Vancouver: University of British Columbia.

Weiler, Jr., W. A. \& Kulhawy, F. H. (1982). Factors affecting stress cell measurements in soil. J. Geotech. Engng Div. Am. Soc. Civ. Engrs 108, GT12, 15291548.

Whitman, R. V., Lambe, P. C. \& Kutter, B. L. (1981). Initial results from a stacked-ring apparatus for simulation of a soil profile. Proc. Int. Conf. on Recent Advances in Geotech. Earthquake Engng and Soil Dynamics 3, 1105-1110. Rolla: University of Missouri. 